\title{
Produção de sementes de quatro ecótipos de Paspalum nativos do Rio Grande do Sul ${ }^{1}$
}

\author{
Rodrigo Ramos Lopes², Lúcia Brandão Franke 3
}

\begin{abstract}
1 Pesquisa financiada com apoio do Conselho Nacional de Desenvolvimento Científico e Tecnológico (CNPq).
2 Doutorando do curso de Pós-graduação em Zootecnia, Faculdade de Agronomia, Universidade Federal do Rio Grande Sul. Bolsista CNPq.

${ }^{3}$ Departamento de Plantas Forrageiras e Agrometeorologia da Faculdade de Agronomia/UFRGS, Caixa Postal 15100, 91501-970, Porto Alegre, RS.
\end{abstract}

RESUMO - O objetivo neste trabalho foi estudar os componentes da produção e da produção de sementes de duas espécies de Paspalum. Foram avaliados dois ecótipos de Paspalum notatum (André da Rocha; e Bagual) e dois de Paspalum urvillei (André da Rocha; e Eldorado do Sul). O delineamento experimental foi completamente casualizado, num esquema fatorial (ecótipos $\times$ dias após o plantio), com cinco repetições aninhadas dentro dos dias após o plantio. Cada espécie foi analisada separadamente para determinação dos componentes da produção e produção de sementes, realizada por amostragens semanais entre 7/11/2006 e 31/3/2007. Foram avaliadas as seguintes variáveis: número de perfilhos vegetativos; número de perfilhos reprodutivos $/ \mathrm{m}^{2}$; porcentagem de perfilhos férteis; número de racemos $/ \mathrm{m}^{2}$; peso de mil sementes; número de sementes/ inflorescência; número de sementes/racemo; e rendimento de sementes/área. A produção de sementes de Paspalum é prejudicada pelo longo período de florescimento e pela capacidade de retenção das sementes na inflorescência. A produção de sementes difere entre ecótipos, uma vez que os valores médios foram de 47,17 kg/ha (Paspalum notatum André da Rocha), 61,01 kg/ha (Paspalum notatum Bagual), 30,60 kg/ha (Paspalum urvillei André da Rocha) e 47,95 kg/ha (Paspalum urvillei Eldorado do Sul). A produção de sementes dessas espécies é altamente influenciada pelo número de perfilhos reprodutivos, pela porcentagem de perfilhos férteis e pelo peso de mil sementes.

Palavras-chave: Paspalum notatum, Paspalum urvillei, perfilho reprodutivo, perfilho vegetativo

\section{Seed production from four Paspalum ecotypes native from Rio Grande do Sul}

\begin{abstract}
The objective of this study was to investigate components of production and seed production of two Paspalum species. It was evaluated two ecotypes of Paspalum notatum and Bagual) and two ecotypes of Paspalm urvillei (André da Rocha and Eldorado do Sul). It was used a complete randomized experimental design, in a factorial scheme (ecotypes $\times$ days after planting), with five replicates nested within days after planting. Each species was analyzed separately for determination of the components of production and seed production. The variables were measured weekly from November $7^{\text {th }} 2006$ to March $31^{\text {st }}$ 2007. The following variables were evaluated: number of vegetative tillers, number of reproductive tillers $/ \mathrm{m}^{2}$, percentage of fertile tillers, number of racemes $/ \mathrm{m}^{2}$, weight of 1000 seeds, number of seeds/inflorescence, number of seeds/raceme and seed yield per area. Seed production of Paspalum is negatively affected by the long flowering period and by the capacity of retention by the seeds in the inflorescence. Seed production differs among ecotypes inasmuch as mean values were $47.17 \mathrm{~kg} / \mathrm{ha}$ (Paspalum notatum André da Rocha), $61.01 \mathrm{~kg} / \mathrm{ha}$ (Paspalum notatum Bagual), $30.60 \mathrm{~kg} / \mathrm{ha}$ (Paspalm urvillei André da Rocha) and $47.95 \mathrm{~kg} / \mathrm{ha}$ (Paspalm urvillei Eldorado do Sul). Seed production of those species is highly affected by the number of reproductive tillers, by the percentage of fertile tillers and by the weight of 1000 seeds.
\end{abstract}

Key Words: Paspalum notatum, Paspalum urvillei, reproductive tiller, vegetative tiller

\section{Introdução}

No Brasil, o gênero Paspalum engloba o maior número de espécies de gramíneas nativas. O Sul das Américas é o centro de origem e de diversificação genética das espécies desse gênero (Batista, 2005), que compreende cerca de 400 espécies, das quais 130 ocorrem no Brasil (Valls, 2005). As espécies e os ecótipos estão distribuídos principalmente nas regiões Centro-Sul do Brasil, Leste da Bolívia, Norte da Argentina, Paraguai e Uruguai (Batista, 2005).

Inúmeros acessos de Paspalum têm sido incorporados a experimentos de cunho agronômico, devido ao bom valor 
forrageiro e à rapidez de estabelecimento de densa cobertura do solo. Genótipos de P. notatum e P. urvillei nativos do Rio Grande do Sul testados quanto à produção de matéria seca apresentaram expressivos valores de produção de matéria seca total, próximos a 14.000 - $15.000 \mathrm{~kg}$ de MST/ha (Steiner, 2005; Sawasato, 2007), provando o potencial produtivo dessas espécies nativas, chegando a níveis de produção próximos de cultivares de espécies tropicais, como Panicum maximum Jacq (16.600 kg de MST/ha) (Cecato et al., 2000).

Características importantes em uma planta forrageira incluem a produção de forragem de qualidade, a persistência e a capacidade de produzir sementes viáveis. A avaliação do potencial de produção de sementes de materiais nativos é de extrema importância, visto que esse é o meio mais fácil e econômico de propagação e manutenção da população no campo (ressemeadura natural). Segundo Pizarro (2000), a falta de estudos sobre produção e manejo de sementes do gênero Paspalum tem limitado sua multiplicação comercial.

Em gramíneas forrageiras, os componentes da produção de sementes são determinados desde o desenvolvimento vegetativo até as etapas do desenvolvimento reprodutivo, destacando-se o número de inflorescências, o número de flores por inflorescência, a porcentagem de germinação e o peso das sementes (Carámbula, s.d.).

Este trabalho foi realizado com o objetivo de avaliar os componentes da produção de sementes de ecótipos de $P$. notatum e $P$. urvillei, nativos do Rio Grande do Sul, visando incorporar novas referências às espécies.

\section{Material e Métodos}

O experimento foi desenvolvido na Estação Experimental Agronômica da Universidade Federal do Rio Grande do Sul, no município de Eldorado do Sul-RS (3005'52"S, 51³9'08"W e altitude média de $46 \mathrm{~m}$ ), localizada no $\mathrm{km} 47$ da rodovia BR 290, região fisiográfica da Depressão Central. O clima é do tipo Cfa, subtropical úmido com verão quente, segundo classificação de Köppen. A precipitação total média anual na região situa-se em torno de 1.440 mm, com média mensal de $120 \mathrm{~mm}$ (Bergamaschi et al., 2003). Os eventos meteorológicos registrados durante o período experimental foram obtidos na Estação Meteorológica do Departamento de Plantas Forrageiras e Agrometeorologia/UFRGS, localizada a cerca de $10 \mathrm{~m}$ da área experimental (Figura 1).

O solo da unidade experimental pertence à Unidade de Mapeamento São Jerônimo, classificado como Argissolo Vermelho distrófico típico - Pvd (Streck et al., 2008) e tem as seguintes características químicas: pH água: 5,6; índice

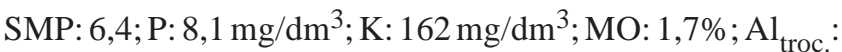

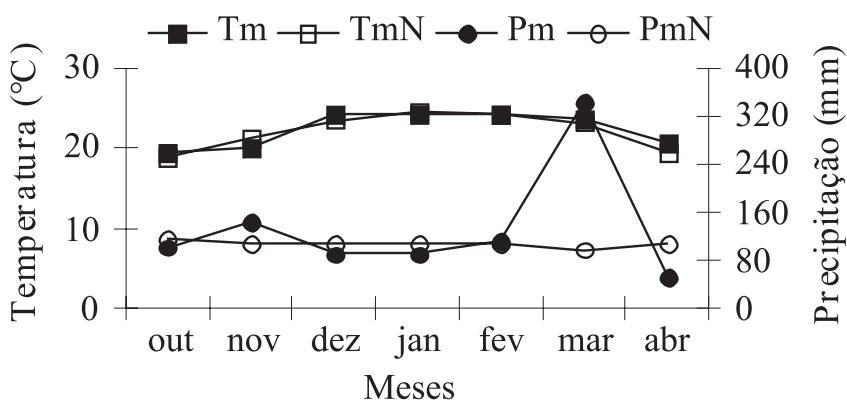

Figura 1 - Temperatura média mensal e precipitação mensal durante o período experimental (2006/2007) e normais para a região.

$0,0 \mathrm{cmol} / \mathrm{dm}^{3} ;$ Ca: $2,6 \mathrm{cmol}_{\mathrm{c}} / \mathrm{dm}^{3} ; \mathrm{Mg}: 1,1 \mathrm{cmol}_{\mathrm{c}} / \mathrm{dm}^{3} ;$ e CTC efetiva: $6,9 \mathrm{cmol}_{\mathrm{c}} / \mathrm{dm}^{3}$. Na área experimental $\left(120,0 \mathrm{~m}^{2}\right)$, foram aplicados calcário dolomítico (2,0 t/ha) e fertilizante 5-20-20 (200 kg/ha) no dia 31/10/2006. Os cálculos foram feitos com base na quantidade de potássio recomendada, com adição 33,3 kg/ha de $\mathrm{N}$ (ureia) e 110,0 kg/ha de $\mathrm{P}_{2} \mathrm{O}_{5}$ (superfosfato triplo).

A instalação do experimento foi realizada com mudas, cuja produção foi feita no outono e mantidas em casa de vegetação durante o inverno. Foram plantadas 63 mudas de $P$. notatum e $P$. urvillei por parcela, com espaçamento de $25 \mathrm{~cm}$ entre linhas e entre plantas. O delineamento experimental foi completamente casualizado, com cinco repetições, em parcelas de $1,5 \times 2,0 \mathrm{~m}\left(3,0 \mathrm{~m}^{2}\right)$, com espaçamento entre parcelas de $0,5 \mathrm{~m}$. O experimento foi irrigado, quando necessário, utilizando-se quatro aspersores que cobriam a área experimental. As irrigações foram realizadas no plantio e na primeira quinzena de dezembro para garantir a sobrevivência das plantas.

Foram avaliados dois ecótipos de $P$. notatum (André da Rocha e Bagual) e dois ecótipos de $P$. urvillei (André da Rocha e Eldorado do Sul), que foram coletados na Estação Experimental Agronômica da Universidade Federal do Rio Grande do Sul e eram originários de antigos experimentos com material coletado a campo em excursões realizadas pelo estado.

O acompanhamento dos períodos vegetativo e de florescimento e da produção de sementes foi realizado por meio de amostragens semanais entre 7/11/2006 e 31/3/2007, sendo avaliados: a) número de perfilhos vegetativos $/ \mathrm{m}^{2}$ : contagem direta dos colmos em estádio vegetativo, em $0,125 \mathrm{~m}^{2}(0,25 \times 0,50 \mathrm{~m})$ e posteriormente extrapolado para $\mathrm{m}^{2}$; b) número de perfilhos reprodutivos $/ \mathrm{m}^{2}$ : contagem direta dos colmos que formaram inflorescências, em 0,125 $\mathrm{m}^{2}$ $(0,25 \times 0,50 \mathrm{~m})$ e posteriormente extrapolado para $\mathrm{m}^{2}$; 
c) porcentagem de perfilhos férteis: regra de três entre os colmos de formaram inflorescências e do total de colmos presentes na área $\left(0,125 \mathrm{~m}^{2}\right)$, sendo expresso em porcentagem; d) número de racemos/inflorescência: média do número de racemos de duas inflorescências de cada parcela, escolhidas ao acaso para cada ecótipo estudado; e) produção de sementes/área: coleta e pesagem das sementes limpas provenientes das amostragens semanais para contagem de perfilhos, obtendo-se, assim, a produção de sementes por parcela, expresso em gramas; $\mathrm{f}$ ) peso de mil sementes: média da pesagem de oito subamostras de 100 sementes, multiplicada por 10; g) número de sementes/ inflorescência: regra de três entre o peso de mil sementes e o peso médio de sementes por inflorescência; $h$ ) número de sementes/racemo: regra de três entre o peso de mil sementes e o peso médio de sementes por racemo.

O delineamento experimental foi completamente casualizado, em esquema fatorial (ecótipo $\times$ dias após o plantio) com cinco repetições por ecótipo aninhadas nas datas após o plantio. Cada espécie foi analisada separadamente. Os dados foram submetidos à análise de variância pelo procedimento PROC GLM do programa Statistical Analysis System ${ }^{\circledR}$ versão 9.1.3 (SAS, 2004) e, em caso de diferença significativa, as médias foram comparadas pelo teste Duncan $(\mathrm{P} \leq 0,05)$.

O efeito dos dias após o plantio no número de perfilhos vegetativos, no número de perfilhos reprodutivos e na porcentagem de perfilhos férteis foi analisado por meio de análises de variância e de regressão e os graus de liberdade do fator avaliado foram desdobrados nos efeitos linear, quadrático e cúbico pelo procedimento PROC REG (SAS, 2004), para escolha do modelo de regressão. Foi considerado o maior valor do coeficiente de determinação $\left(\mathrm{R}^{2}\right)$ a $\mathrm{P} \leq 0,05$ de acordo com o teste $\mathrm{F}$, respeitando-se a resposta biológica dos ecótipos.

A matriz de correlação residual de todas variáveis estudadas foi obtida pelo procedimento PROC CORR (SAS, 2004), utilizando-se seis amostragens com cinco repetições de ambos os ecótipos de $P$. notatum e 13 amostragens com cinco repetições de ambos os ecótipos de $P$. urvillei.

$\mathrm{O}$ modelo matemático geral referente à análise das variáveis estudadas foi representado por:

$$
\mathrm{Y}_{\mathrm{ijk}}=\mu+\mathrm{R}_{\mathrm{i}}\left(\mathrm{P}_{\mathrm{k}}\right)+\mathrm{T}_{\mathrm{j}}+\mathrm{P}_{\mathrm{k}}+\mathrm{TP}_{\mathrm{jk}}+\varepsilon_{\mathrm{ijk}}
$$

em que $\mathrm{Y}_{\mathrm{ikj}}=$ variáveis-dependentes; $\mu$ = média de todas as observações; $\mathrm{R}_{\mathrm{i}}\left(\mathrm{P}_{\mathrm{k}}\right)$ = repetições i aninhadas no período $\mathrm{k}$; $\mathrm{T}_{\mathrm{j}}=$ efeito do tratamento $\mathrm{j} ; \mathrm{P}_{\mathrm{k}}=$ efeito do período $\mathrm{k}$; $\mathrm{TP}_{\mathrm{jk}}=$ interação tratamento $\mathrm{k} \times$ período $\mathrm{j} ; \varepsilon_{\mathrm{ikj}}=$ erro aleatório associado a cada observação ijk. Assume-se que $\varepsilon_{\mathrm{ikj}} \sim \mathrm{NID}$ $\left(0, \sigma^{2}\right)$.

\section{Resultados e Discussão}

O número de perfilhos vegetativos de $P$. notatum variou durante o período de avaliação $(\mathrm{P}<0,0001)$ e foi melhor representado por uma regressão cúbica (Figura 2).

O ecótipo André da Rocha apresentou maior variação na emissão de perfilhos vegetativos, que se concentrou mais entre 50 e 75 dias após o plantio (Figura 2a), enquanto o ecótipo Bagual apresentou menor variação no período de avaliação (Figura 2b). Nota-se neste último ecótipo uma estabilização no número de perfilhos vegetativos por mais tempo (50 a 110 dias após o plantio). Singh \& Chatterjee (1965) observaram em $P$. notatum maior afilhamento no verão, com redução expressiva no inverno, possivelmente em decorrência de baixas temperaturas. Elevadas taxas de natalidade de perfilhos no verão foram também observadas em cultivares de Cynodon spp (Carvalho et al., 2001) e em Brachiaria brizantha cv. Marandu (Sbrissia \& Da Silva, 2008). Moreira et al. (2009), em pesquisa com Brachiaria decumbens observaram maiores taxas de aparecimento de perfilhos no verão (dezembro a fevereiro) e menores taxas em março e abril (primeiros meses de outono).

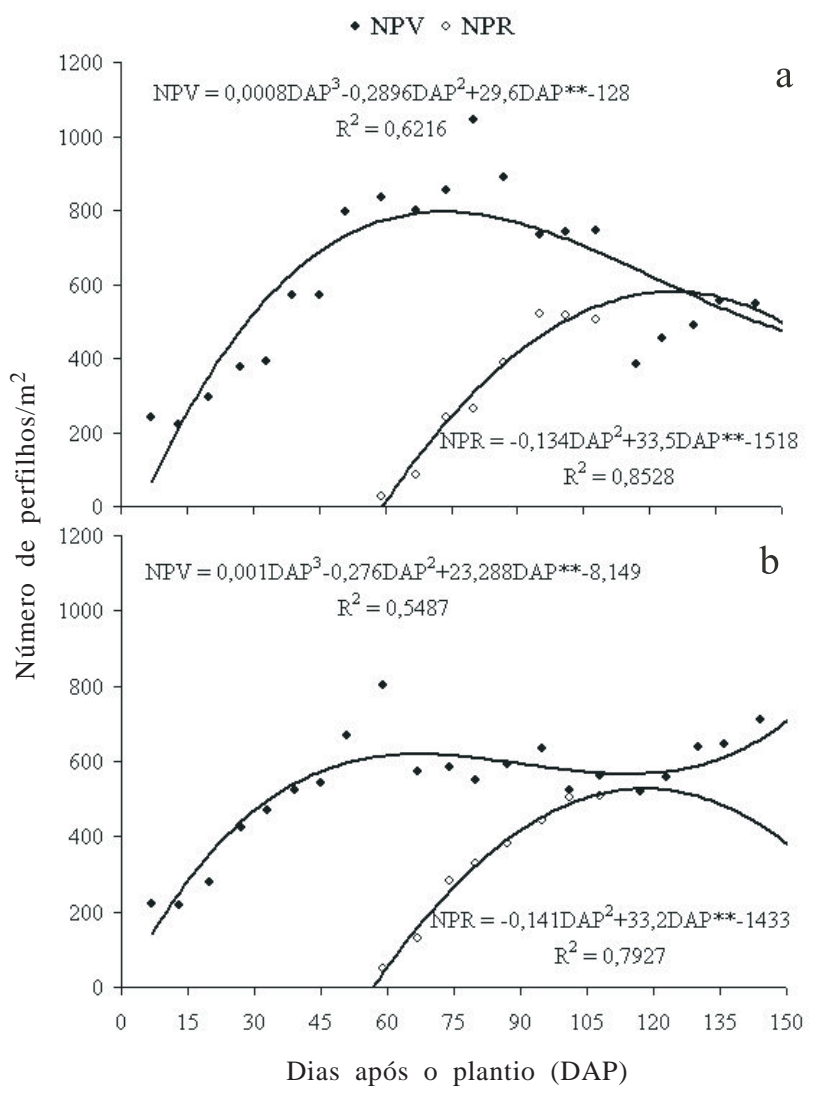

Figura 2 - Número de perfilhos vegetativos e reprodutivos de Paspalum notatum ecótipos André da Rocha (a) e Bagual (b), por $\mathrm{m}^{2}$, após o plantio. 
Os dois ecótipos de $P$. urvillei apresentaram dinâmica de perfilhamento semelhante, ajustando-se melhor ao modelo de regressão cúbica $(\mathrm{P}<0,0001)$ (Figura 3). O ecótipo André da Rocha teve o primeiro e segundo pico aproximadamente aos 50 e 150 dias após o plantio, respectivamente (Figura 3a). No ecótipo Eldorado do Sul, em comparação ao André da Rocha, houve antecipação: o primeiro pico ocorreu aproximadamente aos 40 dias após o plantio e o segundo aos 150 dias após o plantio (Figura 3b). Scheffer-Basso et al. (2002) estudaram o desenvolvimento morfológico de $P$. urvillei e observaram intenso afilhamento durante a estação de crescimento da espécie, comprovando seu vigor. No caso, a maioria dos afilhos foi basilar, o que garante maior preservação dos meristemas e maior tolerância ao pastejo, importante aspecto de manejo.

Com o início do período de florescimento, o surgimento de perfilhos vegetativos apresentou pequena queda no ecótipo André da Rocha ( $P$. notatum) e manteve-se praticamente estável no ecótipo Bagual. O efeito da dominância apical, uma vez que há inibição do crescimento de gemas axilares pelo desenvolvimento da gema apical em inflorescência, pode ter contribuído para isso.

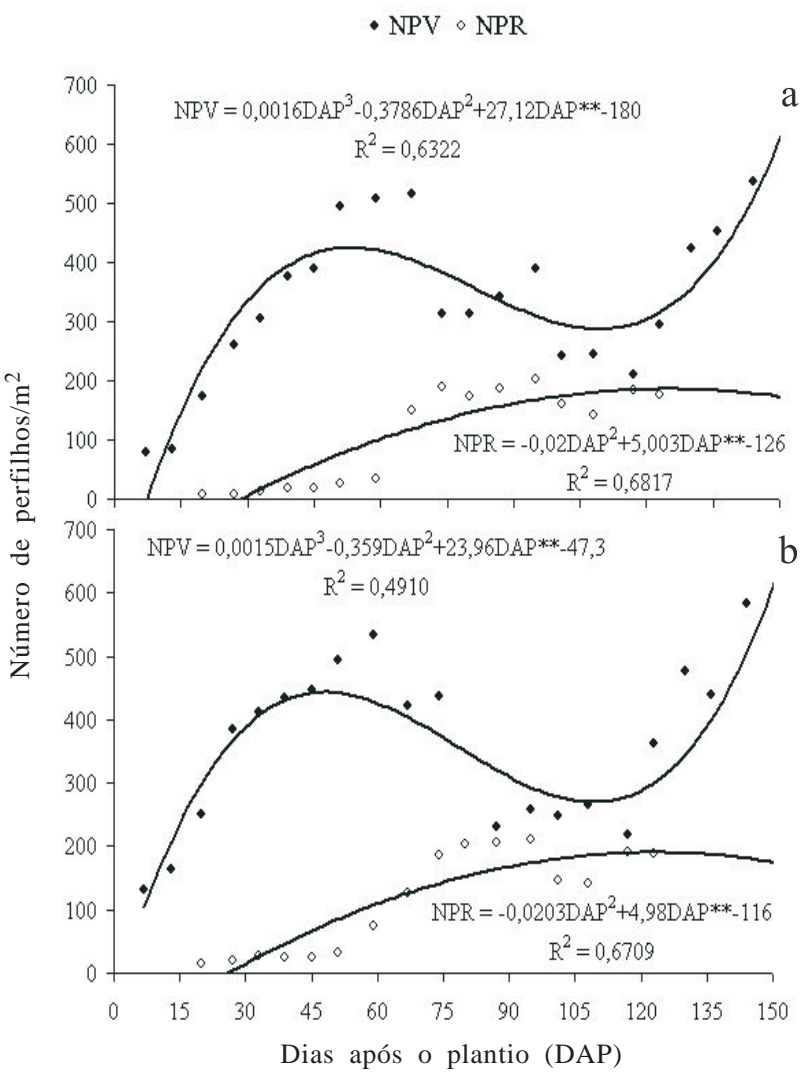

Figura 3 - Número de perfilhos vegetativos e reprodutivos de Paspalum urvillei ecótipo André da Rocha (a) e Eldorado do Sul (b), por $\mathrm{m}^{2}$, após o plantio.
O número de perfilhos reprodutivos $/ \mathrm{m}^{2}$ aumentou até um ponto máximo, a partir do qual a taxa de passagem para o estadio reprodutivo tende a ser decrescente (Figura 2). O início desse comportamento foi observado aos 135 dias após o plantio no ecótipo André da Rocha e mais precocemente no ecótipo Bagual aos 120 dias após o plantio.

O número de perfilhos reprodutivos é um dos componentes mais importantes e determinantes da produtividade de sementes em gramíneas forrageiras (Andrade, 1999). Segundo Souza (2001), a maior produção de perfilhos reprodutivos implica maior número de inflorescências e maior produção final de sementes. Contudo, esse autor mencionou que, dentro de cada espécie ou cultivar, essa característica é altamente influenciada por práticas de manejo agronômico como número, época, altura de cortes e, principalmente, época e quantidade de adubo aplicado.

Nos ecótipos de $P$. urvillei, após o primeiro pico de emissão de perfilhos vegetativos, os mesmos apresentaram queda aproximadamente aos 60 dias após o plantio (Figura 3). O aumento do índice de área foliar causa alteração na qualidade do ambiente luminoso dentro do dossel e contribui para a modificação da taxa de aparecimento de folhas e de novos perfilhos (Deregibus et al., 1983). Com isso, a diminuição progressiva da taxa de aparecimento de folhas com o crescimento do pasto é a principal causa da redução na taxa de perfilhamento (Casal et al., 1987). O perfilhamento também é muito afetado pelo desenvolvimento reprodutivo, pois, durante o início da fase de alongamento dos colmos e o desenvolvimento da inflorescência, o crescimento das gemas de perfilhos é reduzido, podendo ser retomado após a emergência da inflorescência (Marshall, 1987).

O número de perfilhos reprodutivos foi semelhante em ambos os ecótipos de $P$. urvillei e mais bem expresso por regressões quadráticas $(\mathrm{P}<0,0001)$ (Figura 3 ). O P. urvillei apresentou florescimento do início ao fim do período experimental. O florescimento foi progressivo e perdurou durante toda a estação de crescimento. Esse longo período reprodutivo é característica indesejável, tanto para nutrição animal como para produção de sementes (Scheffer-Basso et al., 2002). O número de perfilhos reprodutivos $/ \mathrm{m}^{2}$ aumentou até um ponto máximo, a partir do qual a taxa de passagem para o estádio reprodutivo tendeu à estabilização. O início da estabilização do número de perfilhos reprodutivos em ambos os ecótipos começa após 115 dias do plantio.

De qualquer forma, independentemente do número de perfilhos que potencialmente possam ser produzidos em uma cultura, a grande maioria das espécies de gramíneas forrageiras caracteriza-se por notória precariedade no 
sincronismo da emergência das inflorescências, acarretando sérias dificuldades quando da colheita comercial.

Os ecótipos estudados mostraram comportamento crescente e semelhante na porcentagem de perfilhos férteis e foi melhor ajustado por regressões quadráticas $(\mathrm{P}<0,0001)$ (Figura 4).

O ecótipo Bagual apresentou porcentagem de perfilhos férteis superior à do ecótipo André da Rocha, porém, ao final do período experimental, ambos apresentaram taxas de perfilhos férteis semelhantes (Figura 4a). O ecótipo Eldorado do Sul apresentou crescimento mais acentuado e maiores valores de porcentagem de perfilhos férteis em comparação ao ecótipo André da Rocha (Figura 4b), cujo número de perfilhos reprodutivos foi maior, como visto anteriormente. De acordo com Italiano (2000), o número de perfilhos reprodutivos e a porcentagem de sobrevivência de perfilhos férteis, determinam a densidade de perfilhos férteis, que é o principal fator determinante da produção de sementes em

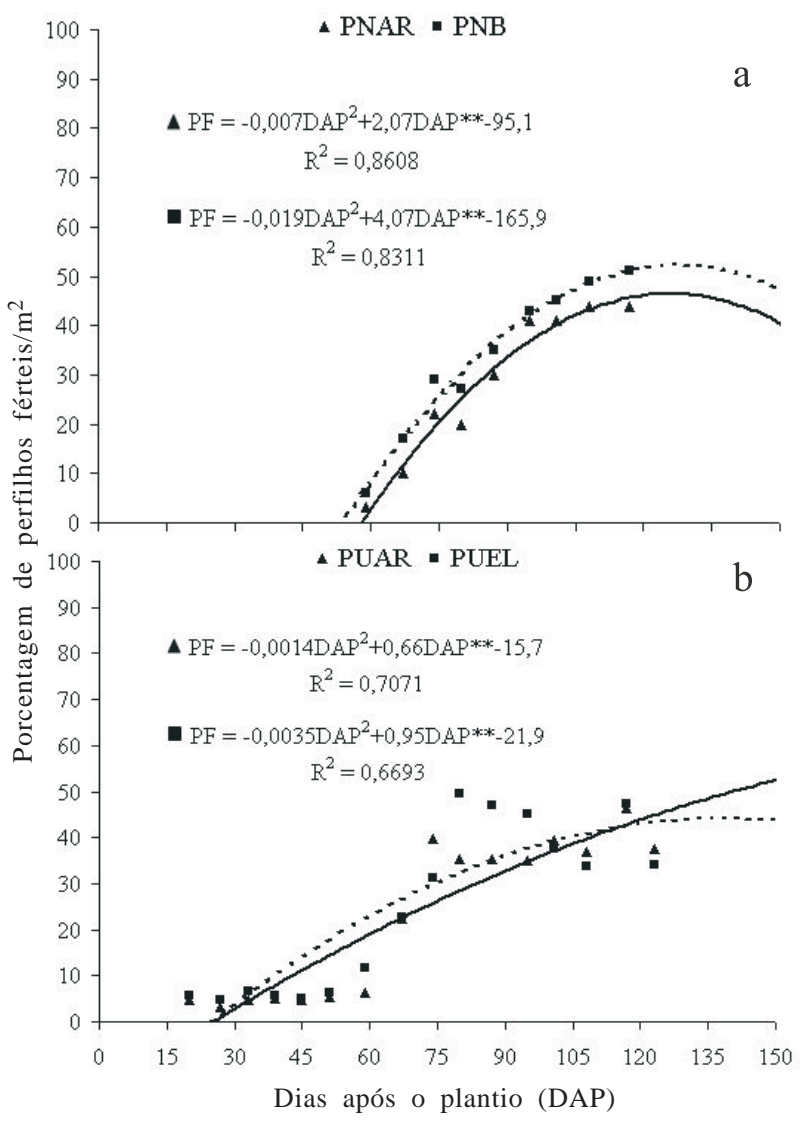

PNAR (linha cheia): P. notatum André da Rocha; PNB (linha tracejada): P. notatum Bagual; PUAR (linha cheia): P. urvillei André da Rocha; PUEL (linha tracejada): P. urvillei Eldorado do Sul.

Figura 4 - Porcentagem de perfilhos férteis de Paspalum notatum (a) e Paspalum urvillei (b), por $\mathrm{m}^{2}$, após o plantio. gramíneas forrageiras. A porcentagem de perfilhos férteis é influenciada pela proporção entre perfilhos vegetativos e aqueles que produziram inflorescências. Desse modo, quanto maior o número de perfilhos reprodutivos (floridos) em relação aos vegetativos, maior os índices de fertilidade. Segundo Humphreys \& Riveros (1986), a produção final de sementes de gramíneas depende do produto de três componentes: número de perfilhos férteis por unidade de área, componente de maior peso sobre a produção de sementes; número de sementes por inflorescência; e peso de mil sementes.

Por meio da análise de variância do número de racemo s/inflorescência, constatou-se que não houve interação ecótipo $\times$ dias após plantio em nenhuma das espécies. Houve significância para ecótipo e dias após plantio em $P$. notatum e efeito isolado dos dias após o plantio em $P$. urvillei $(\mathrm{P} \leq 0,05)$. Observou-se variação no número de racemos/inflorescência em ambos os ecótipos de $P$. notatum a partir dos 51 dias após o plantio até o final do período experimental. Nos ecótipos de $P$. urvillei, a maior variação foi no ecótipo Eldorado do Sul, enquanto o ecótipo André da Rocha mostrou-se uniforme durante o período de 59 a 130 dias após o plantio (Tabela 1).

A desuniformidade no número de racemos de $P$. notatum ecótipo André da Rocha é atribuída ao fato de esse ecótipo apresentar mais inflorescências com dois e três racemos. O ecótipo Bagual apresentou mais inflorescências com três ramificações. Segundo McCarty et al. (2001), a espécie $P$. notatum normalmente apresenta inflorescências que terminam em duas ramificações, raramente três. Essa espécie pode apresentar dois (3-5) ramos unilaterais espiciformes ascendentes conjugados ou subconjugados de 5,0 - 13,5 cm em cada inflorescência (Canto-Dorow et al., 1996).

As primeiras inflorescências surgidas nos ecótipos de $P$. urvillei tiveram número menor de racemos, assim como as últimas, no final do período reprodutivo. O número máximo de racemos/inflorescência concentrou-se nos meses de janeiro (59 a 87 dias após o plantio) e fevereiro (95 a 117 dias após o plantio), com máximo de 18,0 racemos/ inflorescência no ecótipo André da Rocha e de 19,1 racemos/ inflorescência no ecótipo Eldorado do Sul. Esse componente da inflorescência pode ser aumentado por práticas de manejo. Segundo Booman (1972), com aumentos dos níveis de nitrogênio e maiores espaçamentos entre linhas, houve aumento do número de racemos/inflorescência na espécie Chloris gayana. No entanto, Nabinger \& Medeiros (1995) afirmaram que maiores espaçamentos entre plantas possibilitam a emissão de muitos perfilhos, o que determina período longo de emissão de inflorescências. 
Tabela 1 - Número de racemos/inflorescência de $P$. notatum e $P$. urvillei nos dias após o plantio

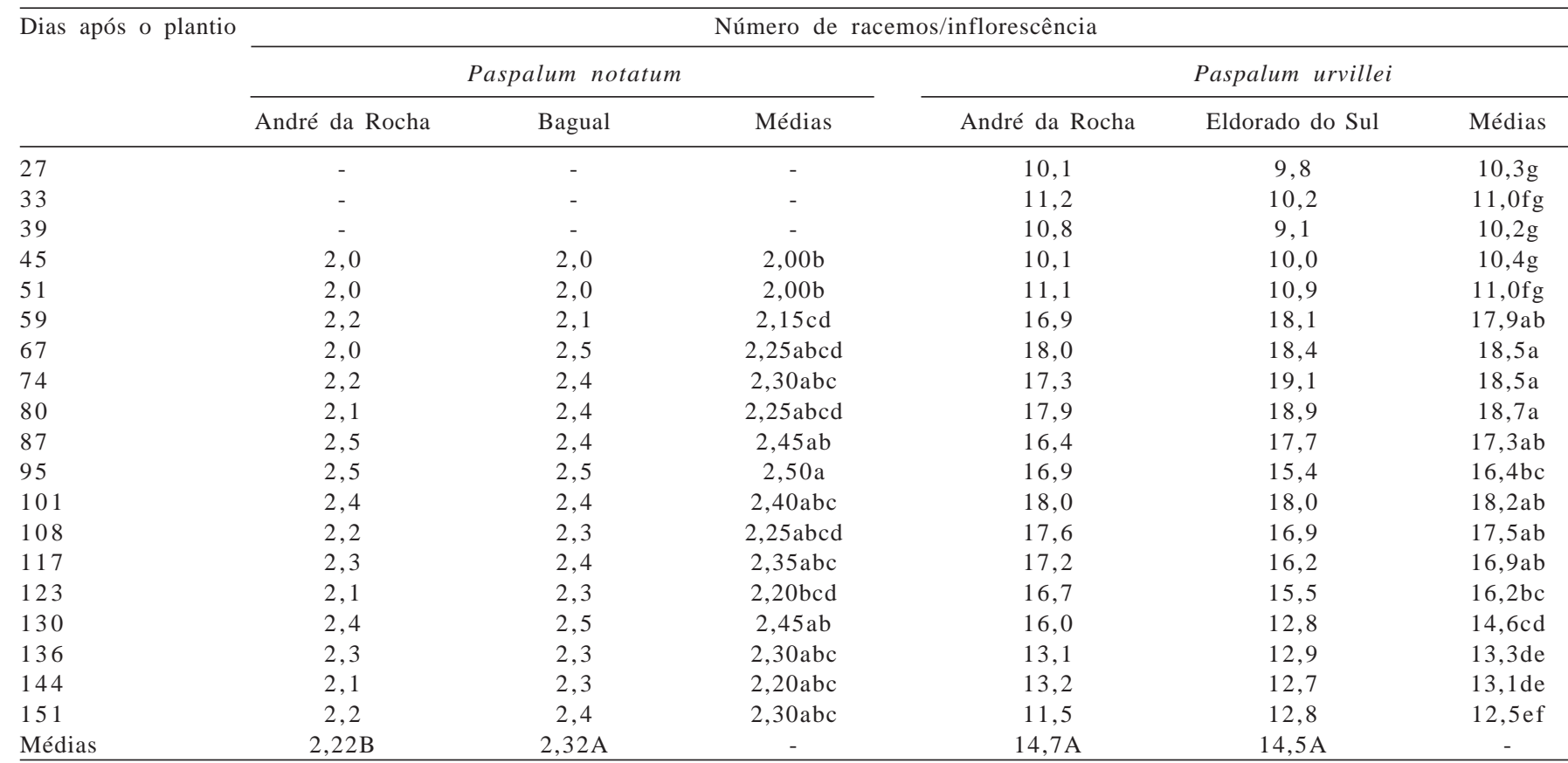

Médias, nas colunas, seguidas de letras minúsculas distintas diferem $(P \leq 0,05)$ entre si pelo teste de Duncan.

Médias, nas linhas, seguidas de letras maiúsculas distintas diferem $(P \leq 0,05)$ entre si pelo teste de Duncan.

O ecótipo, os dias após plantio e a interação ecótipos $\times$ dias após plantio influenciaram $(\mathrm{P}<0,05)$ a produção de sementes. A produção média de sementes de $P$. notatum ecótipo Bagual (61,01 kg/ha) foi maior que no ecótipo André da Rocha (47,17 kg/ha). A produção média de sementes no ecótipo André da Rocha de P. urvillei foi menor (30,60 kg/ha) que no ecótipo Eldorado do Sul (47,95 kg/ha) (Tabela 2).

Os valores encontrados neste trabalho estão abaixo dos encontrados na bibliografia sobre a espécie Paspalum notatum Flügge var. saurae Parodi. No entanto, os ecótipos estudados não sofreram nenhuma seleção e neste trabalho não foram testados efeitos das doses de fertilizantes sobre a produção de sementes. Gates \& Burton (1998), em experimento sobre a produção de sementes com $P$. notatum var. saurae com adubação, observaram produção de $514 \mathrm{~kg} /$ ha de sementes com a aplicação de nitrogênio (224 kg/ha), potássio (25 kg/ha) e potássio (47 kg/ha). Nenhum benefício foi alcançado em níveis acima de $224 \mathrm{~kg}$ N/ha.

O ecótipo André da Rocha ( $P$. notatum) apresentou durante um período prolongado maiores médias de produção de sementes (95 a 130 dias após o plantio). É possível que tenha apresentado maior retenção das sementes nas inflorescências por manter médias iguais durante esse período. No entanto, o ecótipo Bagual apresentou pico destacado e concentrado na produção de sementes aos 108 dias após o plantio.
Nos acessos de $P$. urvillei, houve maior concentração da produção de sementes no ecótipo André da Rocha no período de 80 a 108 dias após o plantio. O ecótipo Eldorado do Sul, no entanto, apresentou período maior de produção de sementes, com o valor máximo observado aos 87 dias após o plantio. Esse pico observado no ecótipo Eldorado do Sul, assim como no ecótipo de P. notatum Bagual, de certo modo, torna-se crítico no momento da colheita, pois a ocorrência de chuvas ou até mesmo a indisponibilidade de maquinário neste período provoca grandes perdas por abscisão dessas sementes.

Nos ecótipos de $P$. notatum, o peso de mil sementes não foi afetado pela interação ecótipo $\times$ dias após plantio, no entanto, o efeito isolado de cada causa da variação foi significativo $(\mathrm{P} \leq 0,05)$. Nos ecótipos de $P$. urvillei, essa variável foi afetada pela interação ecótipo $\times$ dias após plantio e pelo efeito $(\mathrm{P} \leq 0,05)$ de ecótipo e dias após plantio. As sementes mais pesadas, em ambos os ecótipos de $P$. notatum, foram observadas aos 101 dias, enquanto, nos ecótipos de P. urvillei, foram aos 59 dias após o plantio (Tabela 3).

Na espécie $P$. notatum, após 101 dias, foram encontradas as sementes menos pesadas (1,29 g no ecótipo André da Rocha e 1,73g no ecótipo Bagual), enquanto nas demais datas apresentaram maior variação. Gates \& Burton (1998) avaliaram a produção de sementes de Pensacola adubado com nitrogênio, fósforo e potássio por dois anos e obtiveram peso de mil sementes de 1,96 g no primeiro ano e 1,89 g no segundo ano. 
O tamanho final das sementes é influenciado pela competição de nutrientes entre as inflorescências, provavelmente num período precoce da meiose no saco embrionário (Proctor, 1996). Assim, a competição por nutrientes também pode ser influenciada pela hierarquia de perfilhos, ou seja, perfilhos de ordens menores formam sementes mais pesadas por receberem mais assimilados. Em P. maximum Jacq., a translocação de assimilados do perfilho principal para o perfilho primário mais jovem foi menor $(6,5 \%)$ que do perfilho primário para o perfilho principal (14\%), em razão da maior massa do perfilho de menor ordem (Carvalho et al., 2006). Hill \& Watkin (1975), trabalhando com Bromus unioloides, Lolium perenne e Phleum sp., verificaram que a época de emissão da inflorescência influenciou os componentes da produção de sementes, uma vez que os primeiros perfilhos reprodutivos formados proporcionaram maior produção e maior peso de sementes.

Tabela 2 - Produção de sementes e P. notatum e P. urvillei nos dias após o plantio

\begin{tabular}{|c|c|c|c|c|}
\hline \multirow[t]{3}{*}{ Dias após o plantio } & \multicolumn{4}{|c|}{ Produção de sementes (kg/ha) } \\
\hline & \multicolumn{2}{|c|}{ Paspalum notatum } & \multicolumn{2}{|c|}{ Paspalum urvillei } \\
\hline & André da Rocha & Bagual & André da Rocha & Eldorado do Sul \\
\hline 45 & - & - & $1,12 \mathrm{Ae}$ & $0,52 \mathrm{Bf}$ \\
\hline 51 & - & - & 1,49Ae & $0,33 \mathrm{Bf}$ \\
\hline 59 & - & - & $1,23 \mathrm{Ae}$ & 2,39Af \\
\hline 80 & $12,68 \mathrm{Bb}$ & 33,48Afgh & $65,22 \mathrm{Ba}$ & $137,34 \mathrm{Aab}$ \\
\hline 87 & $16,14 \mathrm{Bb}$ & 40,80 Aef & $74,61 \mathrm{Ba}$ & 158,69Аа \\
\hline 95 & $76,40 \mathrm{Ba}$ & 38,76Aefg & $65,98 \mathrm{Ba}$ & $118,19 \mathrm{Ab}$ \\
\hline 101 & $83,14 \mathrm{Ba}$ & $119,86 \mathrm{Ab}$ & $63,15 \mathrm{Ba}$ & 84,85Ac \\
\hline 108 & $66,44 \mathrm{Ba}$ & $162,50 \mathrm{Aa}$ & $67,54 \mathrm{Aa}$ & 52,91Ade \\
\hline 117 & $80,82 \mathrm{Aa}$ & $87,14 \mathrm{Ac}$ & $32,44 \mathrm{Ab}$ & 39,85Ade \\
\hline 151 & $9,68 \mathrm{Bb}$ & $25,32 \mathrm{Ah}$ & 20,37Bbcde & 25,73 Aef \\
\hline Médias & $47,17 \mathrm{~B}$ & $61,01 \mathrm{~A}$ & $30,60 \mathrm{~B}$ & $47,95 \mathrm{~A}$ \\
\hline
\end{tabular}

Médias, nas colunas, seguidas de letras minúsculas distintas diferem $(\mathrm{P} \leq 0,05)$ entre si pelo teste Duncan.

Médias, nas linhas, seguidas de letras maiúsculas distintas diferem $(P \leq 0,05)$ entre si pelo teste Duncan.

Tabela 3 - Peso de mil sementes de P. notatum e P. urvillei nos dias após o plantio

\begin{tabular}{|c|c|c|c|c|c|}
\hline \multirow[t]{3}{*}{ Dias após o plantio } & \multicolumn{5}{|c|}{ Peso de mil sementes (g) } \\
\hline & \multicolumn{3}{|c|}{ Paspalum notatum } & \multicolumn{2}{|c|}{ Paspalum urvillei } \\
\hline & André da Rocha & Bagual & Médias & André da Rocha & Eldorado do Sul \\
\hline 45 & - & - & - & $0,582 \mathrm{Ab}$ & 0,430Bfg \\
\hline 51 & - & - & - & $0,535 \mathrm{Acd}$ & $0,617 \mathrm{Bb}$ \\
\hline 59 & - & - & - & 0,675Aa & 0,707Aa \\
\hline 80 & 1,37 & 2,07 & $1,72 \mathrm{e}$ & $0,455 \mathrm{Bef}$ & $0,527 \mathrm{Ac}$ \\
\hline 87 & 1,33 & 1,92 & 1,63ef & 0,437Aefg & 0,445 Aef \\
\hline 95 & 1,83 & 2,52 & $2,18 b$ & 0,420Agh & 0,475 Bde \\
\hline 101 & 2,05 & 2,78 & $2,42 \mathrm{a}$ & 0,407Bgh & 0,447 Aef \\
\hline 108 & 1,29 & 1,73 & $1,51 \mathrm{f}$ & $0,405 \mathrm{Bh}$ & 0,412Ag \\
\hline 117 & 1,53 & 2,23 & $1,88 \mathrm{~d}$ & $0,425 \mathrm{Afgh}$ & $0,282 \mathrm{Bj}$ \\
\hline 151 & 1,73 & 2,49 & $2,11 b$ & $0,462 \mathrm{Ae}$ & $0,440 \mathrm{Bfg}$ \\
\hline Médias & $1,64 \mathrm{~B}$ & $2,29 \mathrm{~A}$ & - & $0,497 \mathrm{~A}$ & $0,465 \mathrm{~A}$ \\
\hline
\end{tabular}

Médias, nas colunas, seguidas de letras minúsculas distintas diferem $(\mathrm{P} \leq 0,05)$ entre si pelo teste de Duncan.

Médias, nas linhas, seguidas de letras maiúsculas distintas diferem $(P \leq 0,05)$ entre si pelo teste de Duncan. 
O período de maior número de racemos/inflorescência em $P$. urvillei coincide com os menores pesos de mil sementes em ambos os ecótipos (Tabelas 1 e 3). A formação de numerosas inflorescências e racemos/inflorescência gerou sementes menores, como resultado da competição intrínseca de fotoassimilados.

Para o número de sementes/inflorescência dos ecótipos de $P$. notatum, a análise de variância apresentou significância entre ecótipos, dias após plantio e suas interação (P£0,05). Não houve interação entre os ecótipos de $P$. urvillei. Houve significância $(\mathrm{P} £ 0,05)$ somente dos dias após plantio. No ecótipo André da Rocha (P. notatum), o maior número de sementes/inflorescência concentrou-se aos 95 dias após o plantio, enquanto no ecótipo Bagual o valor máximo foi encontrado aos 80, 87 e 108 dias após o plantio. Nos ecótipos de $P$. urvillei, o maior número de sementes/inflorescência ocorreu aos 101 dias após o plantio (Tabela 4).

Em média, o ecótipo Bagual (P. notatum) foi superior ao ecótipo André da Rocha, possivelmente por apresentar racemos mais longos e grande quantidade de inflorescências com três ramificações. O número de sementes/inflorescência merece atenção, pois uma importante característica de gramíneas forrageiras é sua incapacidade de reter, por muito tempo, as sementes maduras conectadas às inflorescências, uma possível explicação para a grande variação encontrada entre as amostragens neste trabalho. De acordo com Souza (2001), essa ruptura ocorre depois que a semente alcança a maturidade, ou antes, se ocorrer estresse por chuvas excessivas, ventos fortes, deficiências nutricionais, hídrica ou luminosa.

O número de sementes/racemo em todos os ecótipos estudados foi influenciado $(\mathrm{P} \leq 0,05)$ pelos dias após o plantio, ecótipos e pela interação ecótipos $\times$ dias após o plantio. No ecótipo André da Rocha ( $P$. notatum), o maior número de sementes/racemo concentrou-se aos 95 dias após o plantio, enquanto no ecótipo Bagual os maiores valores foram observados aos 80 e 108 dias após o plantio. Nos ecótipos de $P$. urvillei, o maior número de sementes/ racemo concentrou-se aos 101 dias após o plantio, enquanto, no ecótipo Eldorado do Sul, os maiores valores foram observados aos 151 dias após o plantio (Tabela 5).

A maior quantidade média de sementes/racemo de P. notatum foi observada no ecótipo Bagual (99,5 sementes/ racemo) em comparação ao ecótipo André da Rocha (48,1 sementes/racemo). O fato de o ecótipo André da Rocha apresentar valores mais baixos pode ser explicado pelo menor tamanho dos racemos. O número máximo de sementes/ racemos de $P$. urvillei foi observado no mesmo período do maior número de sementes/inflorescência. Essas duas variáveis estão diretamente associadas, ou seja, uma depende da outra. O ecótipo Eldorado do Sul não teve o mesmo comportamento, no entanto, houve uma concentração das maiores médias do número de sementes/racemo no mesmo período encontrado para o máximo número de sementes/ inflorescência, fato explicado pela possível perda de sementes por degrana no período das amostragens, característica marcante na produção de sementes em gramíneas forrageiras.

Tabela 4 - Número de sementes/inflorescência de $P$. notatum e $P$. urvillei nos dias após o plantio

\begin{tabular}{|c|c|c|c|c|c|}
\hline \multirow[t]{3}{*}{ Dias após plantio } & \multicolumn{5}{|c|}{ Número de sementes/inflorescência } \\
\hline & \multicolumn{2}{|c|}{ Paspalum notatum } & \multicolumn{3}{|c|}{ Paspalum urvillei } \\
\hline & André da Rocha & Bagual & André da Rocha & Eldorado do Sul & Médias \\
\hline 39 & - & - & 334,5 & 506,7 & 420,6ghi \\
\hline 45 & - & - & 289,1 & 175,1 & 231,9i \\
\hline 51 & - & - & 506,8 & 112,0 & 309,7hi \\
\hline 59 & - & - & 466,5 & 579,5 & $523,2 \mathrm{fgh}$ \\
\hline 80 & $137,0 \mathrm{Bc}$ & $309,2 \mathrm{Aab}$ & 987,9 & 940,3 & $964,1 \mathrm{bcd}$ \\
\hline 87 & $140,2 \mathrm{Bc}$ & $269,4 \mathrm{Aabc}$ & 1125,6 & 1156,0 & $1140,8 \mathrm{ab}$ \\
\hline 95 & $184,8 \mathrm{Aa}$ & $165,4 \mathrm{Ae}$ & 864,1 & 970,2 & 917,0 bcd \\
\hline 101 & 100,0 Bde & $241,4 \mathrm{Abcd}$ & 1266,8 & 1268,8 & $1267,7 a$ \\
\hline 108 & $149,8 \mathrm{Bbc}$ & $328,6 \mathrm{Aa}$ & 800,8 & 797,2 & 799,1cde \\
\hline 117 & 99,0Bde & $246,0 \mathrm{Abcd}$ & 705,7 & 720,1 & 713,1def \\
\hline 151 & $42,2 \mathrm{Bf}$ & 212,6Acde & 622,9 & 1074,7 & 848,8 cde \\
\hline Médias & $116,9 \mathrm{~B}$ & $228,1 \mathrm{~A}$ & $704,5 \mathrm{~A}$ & $775,8 \mathrm{~A}$ & - \\
\hline
\end{tabular}

Médias, nas colunas, seguidas de letras minúsculas distintas diferem $(\mathrm{P} \leq 0,05)$ entre si pelo teste Duncan.

Médias, nas linhas, seguidas de letras maiúsculas distintas diferem $(P \leq 0,05)$ entre si pelo teste Duncan. 
Na literatura consta que práticas de manejo como a aplicação de nitrogênio, em geral efetuada no estadio vegetativo e por ocasião da iniciação floral, tem efeitos positivos sobre a maioria dos componentes, como: número de inflorescências, número de sementes por inflorescências e número de sementes por racemo, o que aumenta a produção de sementes (Humphreys \& Riveros, 1986).

Os estudos sobre a produção de sementes de determinada espécie sempre buscam, de certa forma, identificar, quantificar e correlacionar os componentes da produção com a produção propriamente dita. Algumas variáveis apresentaram correlações positivas e negativas, significativas com a produção de sementes em $P$. notatum e $P$. urvillei, comprovando que influenciaram de algum modo a expressão dessa variável (Tabela 6).

Entre as variáveis consideradas, a que mais se correlacionou com a produção de sementes foi o número de perfilhos reprodutivos ( $\mathrm{r}=0,71$ e 0,73$)$. A alta associação

Tabela 5 - Número de sementes/racemo de P. notatum e P. urvillei nos dias após o plantio

\begin{tabular}{|c|c|c|c|c|}
\hline \multirow[t]{3}{*}{ Dias após o plantio } & \multicolumn{4}{|c|}{ Número de sementes/racemo } \\
\hline & \multicolumn{2}{|c|}{ Paspalum notatum } & \multicolumn{2}{|c|}{ Paspalum urvillei } \\
\hline & André da Rocha & Bagual & André da Rocha & Eldorado do Sul \\
\hline 39 & - & - & $31,0 \mathrm{Bd}$ & 55,5Abcde \\
\hline 45 & - & - & $29,7 \mathrm{Ad}$ & $17,7 \mathrm{Af}$ \\
\hline 51 & - & - & 47,1 Acd & $10,8 \mathrm{Bf}$ \\
\hline 59 & - & - & $28,7 \mathrm{Ad}$ & 31,8 Aef \\
\hline 67 & - & - & 35,9Acd & 52,1 Abcde \\
\hline 74 & 50,2 Bde & $78,2 \mathrm{Abc}$ & $55,4 \mathrm{Aabc}$ & 57,9Abcd \\
\hline 80 & $56,9 \mathrm{Bcd}$ & $147,2 \mathrm{Aa}$ & 54,7Aabc & 50,0Acde \\
\hline 87 & $58,6 \mathrm{Bbcd}$ & $107,8 \mathrm{Ab}$ & $68,3 \mathrm{Aab}$ & 65,0Aabcd \\
\hline 95 & $74,0 \mathrm{Aa}$ & $66,2 \mathrm{Ac}$ & $52,6 \mathrm{Abc}$ & 65,3Aabcd \\
\hline 101 & $41,8 \mathrm{Bef}$ & $100,6 \mathrm{Ab}$ & $73,9 \mathrm{Aa}$ & $72,6 \mathrm{Aabc}$ \\
\hline 108 & $65,0 \mathrm{Babc}$ & $149,2 \mathrm{Aa}$ & 44,8 Acd & 48,2Acde \\
\hline 117 & 41,2Bef & $106,8 \mathrm{Ab}$ & 44,1 Acd & 53,3Abcde \\
\hline 123 & $34,2 \mathrm{Bf}$ & $82,8 \mathrm{Abc}$ & 37,2 Acd & 45,3Ade \\
\hline 130 & $69,4 \mathrm{Aab}$ & $64,8 \mathrm{Ac}$ & 41,6Acd & 54,1 Abcde \\
\hline 136 & $34,4 \mathrm{Bf}$ & $95,2 \mathrm{Abc}$ & 48,0Abcd & 53,0Abcde \\
\hline 144 & $33,4 \mathrm{Bf}$ & $103,0 \mathrm{Ab}$ & $45,9 B c d$ & 75,9Aab \\
\hline 151 & $17,6 \mathrm{Bg}$ & $92,6 \mathrm{Abc}$ & $54,3 \mathrm{Ba}$ & $85,9 \mathrm{Aa}$ \\
\hline Médias & $48,1 \mathrm{~B}$ & 99,5A & $46,6 \mathrm{~B}$ & $52,6 \mathrm{~A}$ \\
\hline
\end{tabular}

Médias, nas colunas, seguidas de letras minúsculas distintas diferem $(\mathrm{P} \leq 0,05)$ entre si pelo teste Duncan.

Médias, nas linhas, seguidas de letras maiúsculas distintas diferem $(P \leq 0,05)$ entre si pelo teste Duncan.

Tabela 6 - Correlações simples entre os componentes da produção de sementes de $P$. notatum e $P$. urvillei

Perfilhos Perfilhos Perfilhos Racemos/ Peso de Sementes/ Sementes/ Produção

vegetativos reprodutivos férteis (\%) inflorescência mil sementes inflorescência racemo de sementes

Perfilhos vegetativos Perfilhos reprodutivos Perfilhos férteis (\%) Racemos/inflorescênia Peso de mil sementes Sementes/inflorescência Sementes/racemo Produção de sementes

Perfilhos vegetativos Perfilhos reprodutivos Perfilhos férteis (\%) Racemos/inflorescênia Peso de mil sementes Sementes/inflorescência Sementes/racemo Produção de sementes
Paspalum notatum

$\begin{array}{rcccl}0,01 & -0,17 & 0,23 & 0,25 & 0,03 \\ 0,19 & 0,72 * * & -0,62^{* *} & -0,62 * * & 0,71^{* *} \\ 0,14 & 0,63^{* *} & -0,63^{* *} & -0,64 * * & 0,46 * \\ - & 0,26 & -0,17 & -0,19 & 0,11 \\ & - & -0,65 * * & -0,66 * * & 0,66 * * \\ & & - & 0,99 * * & -0,62 * * \\ & & & - & -0,62 * *\end{array}$

\section{Paspalum urvillei}

$\begin{array}{rrrrr}0,02 & -0,09 & 0,12 & 0,04 & -0,01 \\ 0,02 & -0,40 * & 0,21 & 0,22 & 0,73^{*} * \\ 0,03 & -0,05 & -0,02 & 0,02 & 0,34^{*} \\ - & 0,13 & 0,09 & -0,29 & -0,11 \\ & - & -0,11 & -0,18 & -0,33^{*} \\ & & - & 0,87 * * & 0,17 \\ & & & - & 0,21\end{array}$

** Significativo a $1 \%$ de probabilidade pela estatística t $(\mathrm{P} \leq 0,01)$.

* Significativo a $5 \%$ de probabilidade pela estatística t $(\mathrm{P} \leq 0,05)$. 
encontrada entre estes componentes está de acordo com Carámbula (s.d.) que aponta o número de perfilhos reprodutivos como um dos componentes mais importantes para obtenção de uma satisfatória produção de sementes em gramíneas forrageiras.

Outras correlações de interesse mostraram-se significativas, por exemplo: porcentagem de perfilhos férteis $\times$ produção de sementes $(\mathrm{r}=0,46$ e 0,34$)$. Logo, se há alto surgimento de perfilhos reprodutivos, haverá maior porcentagem de perfilhos férteis $(r=0,64$ e 0,57$)$ e maior número de inflorescências por unidade de área.

O peso de mil sementes está diretamente correlacionado à produção de sementes $(\mathrm{r}=0,66)$ em Paspalum notatum. $\mathrm{O}$ resultado encontrado neste estudo está de acordo com relatos de Humphreys \& Riveros (1986) que atribuíram ao produto entre o peso das sementes, número de sementes/ inflorescência e número de perfilhos férteis a produção final de sementes de gramíneas forrageiras. No entanto, em $P$. urvillei, o peso de mil sementes está inversamente associado à produção de sementes. Observaram-se relações entre outros componentes, comprovando que há certa compensação entre eles. O número de sementes/ inflorescência e o número de sementes/racemo apresentaram associações negativas com a produção final de sementes, possivelmente pela compensação com o peso de mil sementes, ou seja, quanto maior o peso das sementes, menor o número de sementes/inflorescência.

A produção de sementes por área representa a integração das produções individuais de todos os perfilhos que compõem a pastagem. É necessário conhecer o padrão de perfilhamento por planta e como esse padrão é alterado numa condição de comunidade. A elucidação da dinâmica de perfilhamento de espécies forrageiras nativas, relacionada à produção de sementes, parece ser o caminho mais curto e promissor para se obterem resultados mais efetivos sobre a baixa produção de sementes de gramíneas forrageiras.

\section{Conclusões}

A produção de sementes de Paspalum no Sul do Brasil tem problemas decorrentes do florescimento contínuo e do curto intervalo do florescimento pleno ao início da abscisão das sementes, o que causa dificuldades na colheita. Nos ecótipos de $P$. notatum, a produção de sementes é altamente influenciada pelo número de perfilhos reprodutivos, pela porcentagem de perfilhos férteis e pelo peso de mil sementes. Os ecótipos Bagual e Eldorado do Sul apresentam maior produção de sementes no primeiro ano de avaliação.

\section{Referências}

ANDRADE, R.P. Situação atual e perspectivas da produção e pesquisa em sementes de forrageiras tropicais. Planaltina: EMBRAPA Cerrados, 1999. 28p. (Documentos, 11).

BATISTA, L.A.R.; GODOY, R. Capacidade de produção de sementes em acessos do gênero Paspalum. Revista Brasileira de Zootecnia, v.27, n.5, p.841-847, 1998.

BERGAMASCHI, H. Clima da estação experimental da UFRGS (e região de abrangência). Porto Alegre: UFRGS, 2003. 78p.

BOONMAN, J.G. Experimental studies on seed production of tropical grasses in Kenya. 1 General introduction and analysis of problems. Netherlands Journal Agricultural Science, v.19, n.1, p.23-36, 1971.

CANTO-DOROW, T.S.; LONGHI-WAGNER, H.M.; VALLS, J.F.M Revisão taxonômica das espécies de Paspalum grupo Notata (Poaceae - Paniceae) do Rio Grande do Sul, Brasil. Iheringia, v.47, p.3-44, 1996.

CARÁmBUlA, M. Producción de semillas de plantas forrajeras. Montevideo: Hemisferio Sur, [s.d.]. 518p.

CARVALHO, D.D.; IRVING, L.J.; CARNEVALLI, R.A. et al. Distribution of current photosynthate in two guinea grass cultivars. Journal Experimental Botany, v.57, n.1, p.2015-2024, 2006.

CARVALHO, C.A.B.; SILVA, S.C.; SBRISSIA, A.F. et al. Demografia do perfilhamento e acúmulo de matéria seca em coastcross submetido a pastejo. Pesquisa Agropecuária Brasileira, v.36, n.1, p.567-575, 2001.

CASAL, J.J.; SÁNCHEZ, R.A.; DEREGIBUS, V.A. Tillering responses of Lolium multiflorum plants to changes of red/farred ratios typical of sparse canopies. Journal of Experimental Botany, v.38, n.1, p.1432-1439, 1987.

CECATO, U.; MACHADO, A.O.; MARTINS, E.N. et al. Avaliação da produção e algumas características da rebrota de cultivares e acessos de Panicum maximum Jacques sob duas alturas de corte. Revista Brasileira de Zootecnia, v.29, n.3, p.660668, 2000 .

DEREGIBUS, V.A.; SÁNCHEZ, R.A.; CASAL, J.J. Effects of light quality on tiller production in Lolium spp. Plant Physiology, v.72, n.1, p.900-902, 1983.

GATES, R.N.; BURTON, G.W. Seed yield and seed quality response of Pensacola and improved Bahiagrasses to fertilization. Agronomy Journal, v.90, n.1, p.607-611, 1998.

HILL, M.J.; WATKIN, B.R. Seed production studies on perennial ryegrass, timothy and prairie grass. Effect of tillers age on tiller survival, ear emergence and seed head components. Journal of British Grassland Society, v.30, n.1, p.63-71, 1975.

HUMPHREYS, L.R.; RIVEROS, F. Tropical pasture seed production, plant production and protection. Roma: FAO, 1986. 203p. (Paper, 8).

ITALIANO, E.C.C. Determinação da época de colheita de sementes do Andropogon gayanus Kunth para a região Meio-Norte do Brasil. Pastura Tropicales, v.22, n.2, p.29-33, 2000.

McCARTY, L.B.; EVEREST, J.W.; HALL, D.W. et al. Color atlas of turfgrass weeds. Michigan: Ann Arbor Press, 2001. $59 \mathrm{p}$.

MARSHALL, C. Physiological aspects of pasture growth. In: SNAYDON, R.W. (Ed.). Managed grasslands analytical studies. Amsterdam: Science Publishing, 1987. p.29-46.

MOREIRA, L.M.; MARTUSCELLO, J.A.; MISTURA, C. et al. Perfilhamento, acúmulo de forragem e composição bromatológica do capim-braquiária adubado com nitrogênio. Revista Brasileira de Zootecnia, v.38, n.9, p.1675-1684, 2009.

NABINGER, C.; MEDEIROS, R.B. Produção de sementes de Panicum maximum Jacq. In: SIMPÓSIO SOBRE MANEJO DA PASTAGEM: O CAPIM COLONIÃO, 12., 1995, Piracicaba. Anais... Piracicaba: FEALQ, 1995. p.59-128.

PIZARRO, E.A. Potencial forrajero del género Paspalum. Pastura Tropicales, v.22, n.1, p.38-45, 2000. 
PROCTOR, P.J. The natural history of pollination. 5.ed. London: [s.n], 1996. 463p.

SAWASATO, J.T. Caracterização agronômica e molecular de Paspalum urvillei Steudel. 2007. 205f. Dissertação (Mestrado em Zootecnia) - Faculdade de Agronomia, Universidade Federal do Rio Grande do Sul, Porto Alegre.

SBRISSIA, A.F.; DA SILVA, S.C. Compensação tamanho/densidade populacional de perfilhos em pastos de capim-marandu. Revista Brasileira de Zootecnia, v.37, n.1, p.35-47, 2008.

SCHEFFER-BASSO, S.M.; RODRIGUES, G.L.; BORDIGNON, M.V. Caracterização morfofisiológica e anatômica de Paspalum urvillei (Steudel). Revista Brasileira de Zootecnia, v.31, n.4, p.1674-1679, 2002.

SINGH, R.D.; CHATTERJEE, B.N. Tillering of perennial grasses in the tropics in India. In: CONGRESSO INTERNACIONAL DE PASTAGENS, 9., 1965, São Paulo. Anais... São Paulo: Alarico, 1965. v.2, p.1075-1079.
SOUZA, F.H.D. Produção de gramíneas forrageiras tropicais São Carlos: EMBRAPA, 2001. 43p.

STATISTICAL ANALYSIS SYSTEM - SAS. SAS OnlineDoc. Version 9.1.3. Cary: SAS Institute, 2004. (CD-ROM).

STEINER, M.G. Caracterização agronômica, molecular e morfológica de acessos de Paspalum notatum Flugge e Paspalum guenoarum Arech. 2005. 137f. Dissertação (Mestrado em Zootecnia) - Faculdade de Agronomia, Universidade Federal do Rio Grande do Sul, Porto Alegre.

STRECK, E.V.; KÄMPF, N.; DALMOLIN, R.S.D. et al. Solos do Rio Grande do Sul. Porto Alegre: EMATER/RS, UFRGS, 2002. 128p.

VALLS, J.F.M. Melhoramento de plantas forrageiras nativas, com ênfase na situação do gênero Paspalum. In: CONGRESSO BRASILEIRO DE MELHORAMENTO DE PLANTAS, 3., 2005, Gramado. Anais... Passo Fundo: Embrapa Trigo; Sociedade Brasileira de Melhoramento de Plantas, 2005. (CD-ROM). 